
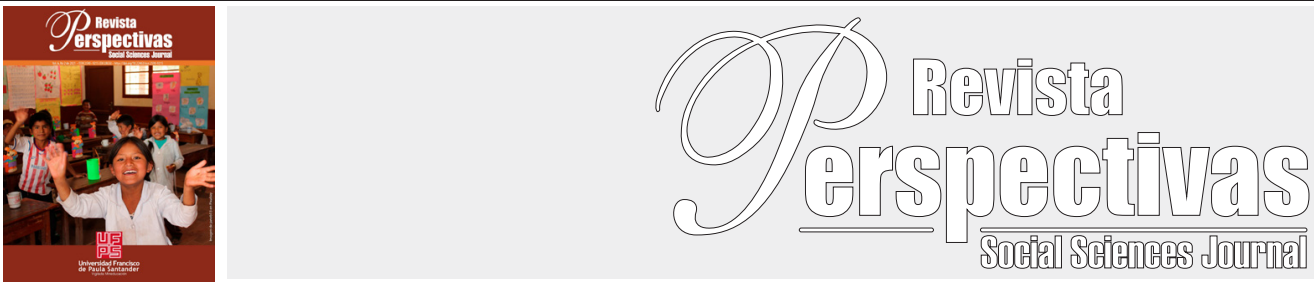

Artículo Original

https://doi.org/10.22463/25909215.2928

\title{
"El Derecho al Olvido como Paradigma en el Rol Responsable de los Medios de
} Comunicación en Internet"

"The Right to be Forgotten as a Paradigm in the Responsible Role of the Media on the Internet."

Pablo Ernesto Lévano-Véliz

Cómo citar: N. Adoumieh Coconas, "La didáctica de la lengua mediada por las TIC Storyjumper como propuesta innovadora en la creación de cuentos.". Revistas Perspectivas, 6, No. 2, 81-91, 2021.

Recibido: August 02, 2020; Aprobado: November 15, 2020.

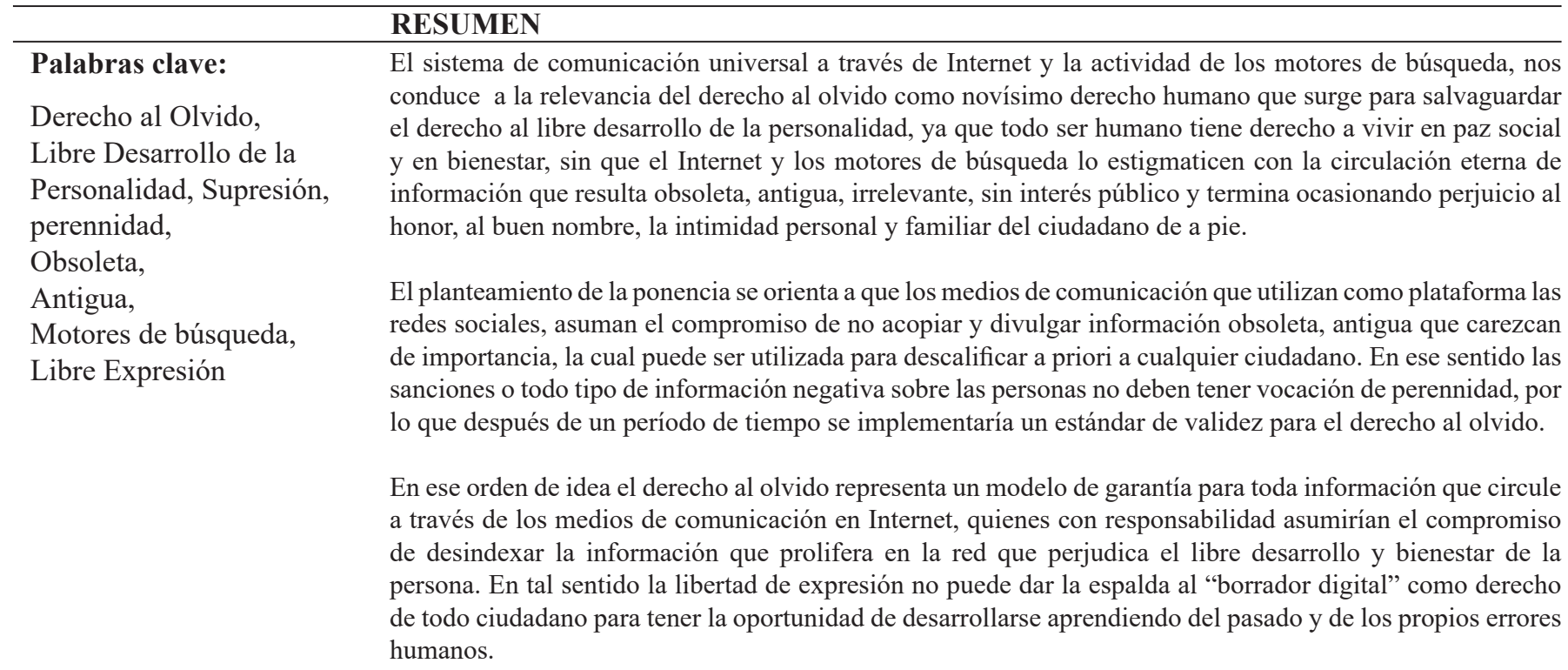




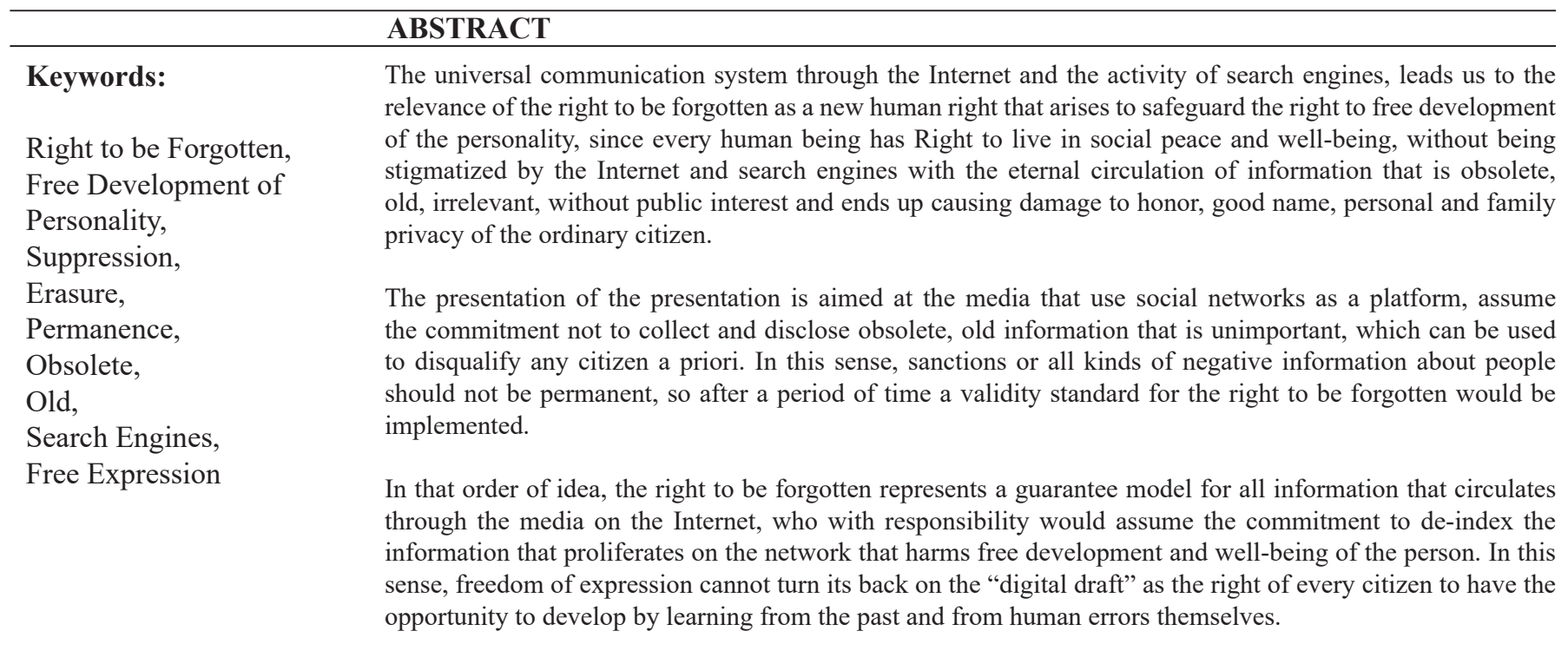

\section{Introducción}

Producto de la Pandemia que vive la humanidad, Internet forma parte del cien por ciento de nuestra nueva normalidad, siendo un vehículo indispensable en la sociedad digital o sociedad de la información, en la que provee y obtiene información en tiempo real y continuo. Internet ha transformado la vida y permite interactuar en sociedad de manera globalizada, mejorando las ventajas económicas y oportunidades en diversos sectores. Es evidente que el derecho al olvido busca que Internet y los motores de búsqueda los cuales ejercen un rol interactivo no estigmaticen a la persona con el intercambio de información, ya que la avalancha de información que proporcionan los medios de comunicación resulta asfixiante para el individuo y en muchos casos conviene dudar de la calidad de la información, ya que se presenta innumerables opciones las cuales pueden ser positivas o negativas.

Por ello consideramos que el derecho al olvido como novísimo derecho humano resulta un paradigma a tomarse en consideración en el rol responsable de los medios de comunicación en Internet, de tal forma que el ejercicio de la libertad de expresión se realice con observancia de la existencia del derecho al olvido cuya razón es salvaguardar el derecho al libre desarrollo de la personalidad, ya que todo ser humano tiene derecho a vivir en paz social $y$ en bienestar.

\section{Internet, Motores de Búsqueda y Redes Sociales}

Toda persona al utilizar los diversos motores de búsqueda en Internet y al ingresar algún dato, tienen acceso a información la cual ha sido indexada por algoritmos de preferencias o perfiles determinados, de esa forma los criterios de búsqueda son determinantes para ubicar de manera rápida la información que se busca en Internet.

La información que circula en Internet a través de los diversos motores de búsqueda en muchos casos resulta falsa u obsoleta, incluso resulta desconocida por el propio titular del dato, lo cual genera desazón en el interesado.

Somos parte de un mundo interconectado, donde las interacciones, las búsquedas en internet, nuestras ubicaciones, los likes, etc, todo queda registrado en tiempo real y vinculado con nuestra identidad, en ese sentido el flujo de los datos y las diversas informaciones permanecen en la red ad aeternum. 
Román Cendoya, autor del libro Revolución. Del Homo sapiens al Homo digitalis reflexiona sobre ciertos aspectos de la vida cotidiana y el rol que la tecnología juega en la misma, siendo evidente la utilización intensiva de mails, mensajes de texto, páginas web, redes sociales y demás aplicativos. Asimismo, Moisés Naím, señala: "En estos tiempos, el solo hecho de que existimos como individuos genera una montaña de datos que - queramos o no - las nuevas tecnologías captan y procesan. Teléfonos móviles, cámaras, computadoras, sensores y plataformas como Facebook, Instagram, Twitter, Flickry, los motores de búsqueda están todo el tiempo recogiendo información sobres nuestras conductas individuales y transformando esos datos en información utilizable - para bien y para mal." (Diario El Tiempo, 2020)

Internet, la $<$ red de las redes $>$ es un prodigioso instrumento multitarea: trasmite imágenes, pero también texto escrito; abre al diálogo entre los usuarios que se buscan entre ellos e interactúan; y permite una profundización prácticamente ilimitada en cualquier curiosidad. Para orientarse entre tanta abundancia, distingamos tres posibilidades de empleo: 1) una utilización estrictamente práctica, 2) una utilización para el entretenimiento y 3) una utilización educativo-cultural. Sobre el uso de Internet para administrar nuestros asuntos y servicios, la previsión es indudable: los chicos y chicas de hoy serán todos en el futuro <cibernautas prácticos>. Las dudas aparecen en cuanto a los restantes usos. (Sartori, 2018)

Los motores de búsqueda pueden ser examinados como un proveedor de contenidos, que consiste en hallar información publicada o puesta en Internet por terceros, indexarla de manera automática, almacenarla temporalmente y, por último, ponerla a disposición de los internautas según un orden de preferencia determinado (Platero, 2016)

En ese sentido, los motores de búsqueda al indexar la información incorporan el servicio a la web de tal forma que al introducir una palabra y navegar por Internet encontramos una lista de resultados ordenados por algoritmos los cuales se clasifican de acuerdo con la relevancia del contenido.

Los motores de búsqueda son servicio de variada tipología que, mediante el uso de algoritmos específicos, facilitan al usuario digital la búsqueda de información en Internet. En ese sentido, en función del tipo de formato o del tipo de soporte en que se halle la información que se pretende encontrar, pueden clasificarse en motores de búsqueda de imágenes, vídeos y sonidos. Por otro lado, los motores de búsqueda también se encuentran dirigidos específicamente a establecer perfiles de personas sobre la base de los datos personales encontrados en Internet. (Di Pizzo, 2018)

Podemos entender que los buscadores son herramientas que indexan noticias, direcciones, imágenes, videos, etc que se encuentran alojadas en las páginas web y las vincula utilizando los ítems: "tema" "palabra" "voz".

Se advierte entonces que los motores de búsqueda en forma automática recopilan la información de los servidores web, generando índices de búsqueda, trasladando los enlaces, sitios web relacionados con la palabra ingresada por el usuario.

Respecto a las redes sociales, no puede negarse que dichos aplicativos como herramientas del Internet permiten el intercambio de datos, publicidad, información entre los usuarios que han formado una especie de comunidad virtual.

De acuerdo con los expertos, las redes sociales son sistemas y estructuras sociales en los que se realiza un intercambio entre sus miembros y los de una red con los de otra, que puede ser otro grupo u otra organización. Esta comunicación dinámica permite sacar un mejor provecho de los recursos que poseen los miembros de las redes. (Chen, 2013) 
Entonces la tendencia de las redes sociales no solo es publicidad, ya que conlleva expansión de datos, incluso puede desinformar como parte de una estrategia digital.

En la actualidad es innegable que la red social más importante es Facebook, con más de 3000 millones de usuarios, la cual se inició como un sitio de redes sociales de estudiantes universitarios, incluso existen comentarios anecdóticos cuando refieren que existen tres países: China, India y Facebook.

Es de conocimiento que una vez que se comparte información y datos personales en la red, el uso y tráfico de información se realiza sin restricciones incluso ad infinitum, por ejemplo, con Facebook, en caso el usuario decida eliminar su cuenta, sólo podrá desactivar temporalmente la cuenta, manteniéndose todos los datos y la información que se compartió y entregó a través de las redes sociales.

En cuanto a la información que circula por las redes sociales resulta tan diversa que los usuarios suelen intercambiar datos personales, opiniones, titulares de noticias y todo tipo de oferta de servicios y/o productos, revelándose de esta manera las preferencias y los intereses de cada segmento, grupo o persona.

Los diversos motores de búsqueda y la utilización de las redes sociales, a través de los aplicativos respectivos, se convierten a nivel mundial en potentes herramientas del Internet con lo cual las personas pueden compartir, intercambiar todo tipo de información y datos en tiempo real, construyendo comunidades virtuales sujeta a interacción.

En ese orden de ideas se advierte que el usuario al utilizar Internet visita diversas páginas web, lo que ocasiona la indexación de manera predeterminada de resultados o información que atañe a la intimidad y a los datos personales de su titular.
En consecuencia, la importancia del Internet para la humanidad resulta vital y su incremento exponencial se proyecta con mucha intensidad en todas las actividades de la humanidad, adquiriendo en estos tiempos mayor velocidad para una conectividad denominada nueva normalidad.

\section{Derecho al olvido y el derecho fundamental al libre desarrollo de la personalidad}

La característica relevante que se encuentra en toda persona es que goza y es titular de los derechos fundamentales por la condición de ser humano, tal es así que, bajo el ámbito del derecho fundamental al libre desarrollo de la personalidad, lo que se busca es la felicidad entendiéndosele como un derecho inalienable que toda persona humana lo tiene en forma inherente y que se encuentra vinculado a las diversas particularidades de la personalidad, de esta forma es un aporte para la edificación del derecho humano al libre desarrollo de la personalidad y que a su vez guarda interdependencia con los demás derechos humanos. Esta universalidad de sus derechos se encuentra reflejada en diversos instrumentos internacionales.

\section{Derecho fundamental al libre desarrollo de la personalidad en los Convenios Internacionales de Derechos Humanos}

El derecho al libre desarrollo de la personalidad tiene su antecedente en la Declaración Universal de los Derechos Humanos, al referirse que: "Todos los seres humanos nacen libres e iguales en dignidad y derechos (...) debiendo comportarse fraternalmente los unos con los otros". En esa línea el artículo 22 de la referida Declaración señala: "Toda persona, como miembro de la sociedad, tiene derecho a la seguridad social, y a obtener, mediante el esfuerzo nacional y la cooperación internacional, habida cuenta de la organización y los recursos de cada Estado, la satisfacción de los derechos económicos, sociales y culturales, indispensables a su dignidad y al libre desarrollo de su personalidad." 
Entonces la búsqueda de la felicidad es un derecho inalienable que toda persona humana lo tiene en forma inherente y son el aporte para la edificación del derecho humano al libre desarrollo de la personalidad.

El libre desarrollo de la personalidad es un derecho humano y como derecho universal forma parte del status de todo ser humano, haciendo que cada personalidad se encuentre protegida en forma individualizada, ya que todo ser humano ejerce el poder sobre sí mismo, es decir su proyección de vida y felicidad, bajo sus convicciones y creencias personales.

La Convención Americana sobre Derechos Humanos, señala en su preámbulo: "los derechos esenciales del hombre no nacen del hecho de ser nacional de determinado Estado, sino que tienen como fundamentos los atributos de la personalidad humana."

Respecto al Pacto Internacional de Derechos Civiles y Políticos, el Preámbulo se refiere de manera tácita al libre desarrollo de la personalidad, en el extremo de darle reconocimiento.

Entonces la aspiración del libre desarrollo de la personalidad se encuentra unido a la calidad de vida percibida como equilibrio de emociones dentro de un entorno familiar y social. En ese orden de ideas, apreciamos que independientemente a la nacionalidad que tenga la persona, el libre desarrollo de la personalidad forma parte de todo ser humano por su condición de tal. Entonces la titularidad y universalidad es el atributo que acompaña como persona humana.

\section{Derecho fundamental al libre desarrollo de} la personalidad en Perú

Como inmediato antecedente constitucional, corresponde indicar que la Constitución Política del Perú de 1979, consignaba de forma expresa en el artículo 2.1 el derecho al libre desarrollo de la personalidad: "Toda persona tiene derecho a la vida, a un nombre propio, a la integridad fisica y al libre desenvolvimiento de su personalidad."

La vigente Constitución Política del Perú que data de 1993, a través del numeral 1 del artículo 2 ha establecido que toda persona tiene derecho a su libre desarrollo y bienestar, lo cual se encuentra vinculado con el derecho y respeto a la dignidad de la persona.

García Toma (2001) señala que: "El libre desarrollo de la persona significa la plena realización del individuo como ser humano. Supone, el ejercicio de una facultad que reconoce a cada persona la posibilidad de hacer uso de todas sus potencialidades fisicas, intelectuales y morales en su propio beneficio, con la finalidad de alcanzar un nivel de vida cualitativamente mejor. Es el derecho de todo ser humano a lograr la realización de su personalísimo proyecto de vida, lo que es imposible concreción si no se goza de los bienes materiales y espirituales indispensables para una existencia digna y compatible con la condición humana."

En ese orden de ideas, la información y los datos que forman parte del perfil del usuario se almacena por tiempo indefinido en diferentes bases de datos, siendo de fácil acceso por Internet, de tal forma que, al realizar cualquier tipo de búsquedas en la web, queda registrado en la memoria digital, lo cual se convierte en insumo para los diversos motores de búsqueda con el fin de diseñar el perfil del internauta, siendo el objetivo sumarlo a la cadena de comercio.

En el Perú sobre el contenido del derecho al libre desarrollo de la personalidad, el Tribunal Constitucional, ha señalado:

$<$ [e]1 derecho al libre desarrollo garantiza una libertad general de actuación del ser humano en relación con cada esfera de desarrollo de la personalidad. Es decir, de parcelas de libertad natural en determinados ámbitos de la vida, cuyo ejercicio 
y reconocimiento se vinculan con el concepto constitucional de persona como ser espiritual, dotada de autonomía y dignidad, y en su condición de miembro de una comunidad de seres libres (...) Tales espacios de libertad para la estructuración de la vida personal y social constituyen ámbitos de libertad sustraídos a cualquier intervención estatal que no sean razonables ni proporcionales para la salvaguarda y efectividad del sistema de valores que la misma Constitución consagra $>$ (Fundamento 22) (STC No0032-2010-AI/TC)

Entonces la persona humana goza del derecho de alterar, modificar, innovar sobre su proyecto de vida y como tal, esa posibilidad es la que representa la garantía de la esfera privada de la persona frente a los demás, de tal manera que la relación con el Derecho al Olvido se encuentra vinculado con la identidad y ejercicio del libre desarrollo de la personalidad.

El libre desarrollo de la personalidad o conocido comolibre desarrolloy bienestar, también se encuentra vinculado con el derecho a la dignidad, habiendo señalado el Tribunal Constitucional que ambos son ejes centrales del sistema de valores reconocidos por la Carta Magna peruana representando la base y sustento de los demás derechos fundamentales.

Sentencia del Tribunal de Justicia de la Unión Europea - STJUC, 13 mayo 2014, Google Spain, Google Inc. y Agencia Española de Protección de Datos (AEPD), Mario Costeja

El 05 de Marzo de 2010, el Sr Mario Costeja, acudió a la Agencia Española de Protección de Datos - AEPD - y ejerciendo el derecho de oposición al tratamiento de sus datos de carácter personal, presentó reclamo contra el diario "La Vanguardia"; Google Spain y Google Inc. señalando que su nombre aparecía en el buscador de Google, a través de los enlaces del diario "La Vanguardia" del año 1998, en la que se publicitaba que el Sr. Costeja se encontraba sujeto al embargo y la subasta de su inmueble por tener la condición de moroso debido a la deuda ante la Seguridad Social. Esta información al aparecer en Internet y al mantenerse vigente generaba perjuicio a su reputación a pesar de que ya no era deudor.

El petitorio del Sr. Costeja consistía en exigir al medio de comunicación: diario "La Vanguardia" eliminar esas páginas. Además, solicitaba al motor de búsqueda Google elimine sus datos personales de los resultados de dicho motor de búsqueda, ya que carecían de relevancia actual.

La sentencia expedida por el TJUE de fecha 14 de mayo de 2014, en el caso Google vs AEPD, denominado Caso Mario Costeja, resulta el punto de partida del novísimo derecho al olvido, también se le conoce "cancelación de datos en Internet" o "cancelación de datos en los motores de búsqueda".

El referido fallo judicial ha permitido que todo ciudadano de a pie pueda dirigirse y accionar contra los motores de búsqueda, para que no indexen y circulen información y datos que perjudiquen la intimidad y el derecho a la protección de datos del titular.

En ese sentido la importancia de la referida sentencia es que construye las reglas que se convierten en cimientos de observancia para los Estados miembros de la UE., en la aplicación del derecho al olvido.

En el caso Costeja, el fin que persigue el titular del dato es que se proceda a cancelar los datos personales en Internet que sean inadecuados, excesivos o no pertinentes. Dentro de ese orden de ideas el TJUE ha señalado que corresponde aplicar el artículo 6 de la Directiva 95/46 CE, cuyo tenor: "los datos han de ser adecuados, pertinentes y no excesivos, con relación a los fines para los que se recaben y para los que se traten posteriormente, que sean exactos y, cuando sea necesario actualizados." 
En consecuencia, el caso Costeja representa la imagen de un sujeto que hace más de 15 años fue moroso, pero que cumplió con el pago de la deuda, sin embargo, el dato que se publicitaba en Internet mostraba información descontextualizada, de naturaleza inexacta, por lo tanto, el responsable del tratamiento de datos, es decir el motor de búsqueda Google, se encuentra obligado a suprimir o rectificar aquellos datos que no se ajustan a lo establecido en la Directiva 95/46 CE.

Entonces podemos concluir que el derecho al olvido de acuerdo con el Caso Costeja, se encuentra referido a que toda persona como titular de sus datos personales tiene el derecho a que se elimine, borre, suprima de Internet cualquier información personal antigua que resulte perjudicial al individuo

Enfoque sobre contenido, bien jurídico, características y titulares del derecho al olvido

El transcurso del tiempo resulta relevante para la aplicación y reconocimiento del derecho al olvido de tal forma que acompañamos las reflexiones de Viviane Reding, vicepresidenta y Comisaria de Justicia de la UE: "Advierte la importancia del derecho al olvido como medio de garantía efectiva de control de sus datos por parte de los individuos y como respuesta a la tecnología que ofrece hoy ilimitadas posibilidades de almacenamiento, intercambio y difusión, y a la que se pretende oponer un sano principio de ecología informativa. Termina indicando, "Dios perdona y olvida; Internet, nunca."

Simón (2012), define derecho al olvido: "derecho de la ciudadanía a cancelar y oponerse al tratamiento de sus datos personales cuando estos han dejado de ser útiles o necesarios para el propósito con el que fueron recabados o publicados."

Otro enfoque y en esa línea de reflexión Álvarez (2015) comenta: "Se conoce como derecho al olvido, a un interés jurídicamente protegido de los ciudadanos que consiste en lograr efectivamente que sus datos personales no sean localizados por los buscadores en la Red. No se trata de exigir el borrado de los datos porque éstos no son exactos o ciertos, sino porque el titular de estos considera que le perjudican y estima asimismo que no existe ningún fin que legitime la disponibilidad de dichos datos por parte de terceros."

En esa línea encontramos que Simón (2012) señala: “(...) el bien jurídico protegido en el derecho al olvido se encuentra configurado por el libre desarrollo de la personalidad y la protección de datos de carácter personal."

Para tal efecto se ha identificado que dentro de las características del derecho al olvido se ha mencionado que es un derecho subjetivo, cuya titularidad es ejercida de forma individual con autonomía y vinculado con el libre desarrollo de la personalidad y la dignidad humana.

El derecho al olvido busca desplazar la perennidad, la perpetuidad de la información en Internet, la cual se ha impuesto a la realidad física (tiene fronteras delimitadas de espacio, sujeto al recuerdo), ya que las plataformas digitales, no tienen fronteras físicas de espacio. En esa línea de exposición la memoria biológica es reemplazada por la memoria digital o recuerdo on line generado por Internet.

Derecho al olvido, surge frente al avasallante espiral digital de información, que termina por perennizar datos antiguos, obsoletos, descontextualizados, los cuales comprometerían el futuro de las personas. La ponderación y la relevancia pública de los hechos ayudan a resolver el conflicto del derecho al olvido y las libertades informativas.

Internet y las nuevas tecnologías han dado nacimiento a los motores de búsqueda que como plataformas acceden y difunden información en forma rápida y fácil. En consecuencia, estamos frente 
al efecto multiplicador de los motores de búsqueda que terminan reemplazando la frágil memoria de la persona y propician el fin del olvido, el cual antes ocurría de forma natural, sin embargo, ahora Internet representa nueva posibilidad "ad aeternum" de almacenamiento en el universo de la red.

El riesgo de descontextualización de la información que se divulga en Internet es la razón para amparar el derecho al olvido, ya que la información que es pública y de fácil acceso, termina convirtiéndose en una amenaza contra la protección de datos personales y la vida privada. Incluso corresponde mencionar que el derecho al olvido combate la perpetuidad de la información en Internet, en virtud que el interés público no es eterno, por lo tanto, es caduco, transitorio.

\section{Derecho al olvido como paradigma en el rol responsable de los medios de comunicación.}

El Derecho no puede mantenerse estático frente al avance de la tecnología, identificamos que el sistema de comunicación universal a través de Internet y la actividad de los motores de búsqueda, nos conduce a la relevancia del derecho al olvido como novísimo derecho humano que surge para salvaguardar el derecho al libre desarrollo de la personalidad, ya que todo ser humano tiene derecho a vivir en paz social y en bienestar, sin que el Internet y los motores de búsqueda lo estigmaticen con la circulación eterna de información que resulta obsoleta, antigua, irrelevante, sin interés público y termina ocasionando perjuicio al honor, al buen nombre, la intimidad personal y familiar del ciudadano de a pie.

Desafío del derecho al olvido frente a la libertad de expresión en las plataformas de las redes sociales.

Particularmente la libertad de expresión como derecho fundamental no es absoluto y su ejercicio tampoco es ilimitado. Atienza (1997) la entiende como la emisión de juicios y opiniones.
Suele definirse como "la capacidad de recibir los puntos de vista personales del emisor que, en tanto son opinables requieren un carácter básico de congruencia entre lo que se busca señalar y lo que finalmente se declara públicamente." (Exp. $\mathrm{N}^{\mathrm{o}}$ 00006-2009-AI/TC, fj 33)

Para tal efecto la Corte Interamericana de Derechos Humanos en la OC-5/85 señala: "El abuso de la libertad de expresión no puede ser objeto de medidas de control preventivo sino fundamento de responsabilidad para quien lo haya cometido."

El Derecho al Olvido se ha convertido en un fenómeno de impacto frontal frente la Prensa y lo motores de búsqueda en Internet, por lo que resulta relevante identificar la responsabilidad en los medios de comunicación. Sin embargo, en el Perú no existe una regulación legal respecto a la casuística sobre derecho al olvido que proteja la intimidad y honor, entonces dicha carencia es lo que ha motivado nuestra propuesta de su reconocimiento constitucional.

En ese sentido aparece la razonabilidad y proporcionalidad los cuales se utilizarán como criterios para establecer ciertos límites a la libertad de expresión, además destaca la ética responsable, la cual guía el ejercicio del periodismo, con lo cual se busca fortalecer el rol y la credibilidad de los medios de comunicación.

Al identificarse que la libertad de expresión se encuentra unida a la transparencia y a la expresión de valores, corresponde a los medios de comunicación velar por la responsabilidad periodística, manteniendo la ética. Entonces en una sociedad democrática, el reto del derecho al olvido frente a la libertad de expresión es lograr que los medios actúen con responsabilidad salvaguardando la credibilidad de la prensa, asimismo uno de sus efectos es moderar los contenidos que circulan en Internet y los motores de búsqueda, ya que resulta fácil naufragar frente determinada información antigua, obsoleta, irrelevante y que no siendo de 
interés público causa perjuicio al libre desarrollo y bienestar de la persona.

En esa línea de exposición el derecho al olvido es una alerta contra todo aquello que aparece en la red ya que cuestiona su verosimilitud, de tal forma que no pueda ser utilizado para descalificar a priori a cualquier ciudadano.

La memoria y los recuerdos suele menguar con el avance de los años, además es connatural al ser humano no recordar o hacerlo selectivamente, ya que es una forma de que el mal recuerdo no impida avanzar el desarrollo de la persona, sin embargo, ahora nos encontramos con la memoria digital que es ilimitada y de fácil intercambio y divulgación, lo cual impide que pueda operar el olvido, sobre todo cuando encontramos información falsa, inexacta, obsoleta indexada por los motores de búsqueda.

En esa línea de reflexión el profesor Francisco Morales, comentó: “En la era digital la regla es recordar ya que resulta sencillo, fácil y de acceso inmediato de tal manera que la fragilidad de la memoria de antaño ha sido reemplazada por la perpetuidad de la memoria digital colectiva."

El avance sorprendente de Internet permite tener acceso a todo tipo de información y donde el flujo y difusión se realiza sin ningún tipo de filtros, pudiendo causar daños a las personas a nivel universal.

Ahora la perennidad de la información se encuentra "ad aeternum" en Internet, reflejado por el efecto multiplicador de los motores de búsqueda, los cuales aglutinan, acumulan, indexa noticias, opiniones, gustos, etc, es decir todo lo que se encuentre en el Universo de la red.

La utilidad del derecho al olvido representa un valioso aporte para lograr que la libertad de expresión puede limitarse en forma cierta cuando su ejercicio afecte la dignidad del ser humano, honor, libre desarrollo de la personalidad, etc., no obstante, se suscita con frecuencia colisión entre ambos derechos que amerita tomarse en cuenta como problemática de una situación comunicacional del presente siglo.

Respecto la información que comparten diversos medios de comunicación la cual circula en Internet se caracteriza por la carencia o la falta de observancia de un estándar de información de calidad, de tal manera que la información que circula en redes sociales en la gran mayoría de los casos no se ajusta ni es ejercida con profesionalismo ético de los medios tradicionales.

\section{Conclusiones}

- La sentencia expedida por el TJUE de fecha 14 de mayo de 2014, en el caso Google vs AEPD, denominado como el Caso Mario Costeja, resulta el punto de partida del novísimo derecho al olvido. El fallo judicial ha permitido que todo ciudadano de a pie pueda dirigirse y accionar contra los motores de búsqueda, para que no indexen y circulen información y datos que perjudiquen la intimidad y el derecho a la protección de datos del titular. En el caso Costeja, el fin que persigue el titular del dato es que se proceda a cancelar los datos personales en Internet que sean inadecuados, excesivos o no pertinentes.

-Derecho al olvido busca que Internet y los motores de búsqueda los cuales ejercen un rol interactivo no estigmaticen a la persona con el intercambio de información, ya que la avalancha de información que proporcionan los medios de comunicación resulta asfixiante para el individuo y en muchos casos conviene dudar de la calidad de la información, ya que se presenta innumerables opciones las cuales pueden ser positivas o negativas.

-Derecho al olvido como novísimo derecho humano resulta un paradigma a tomarse en consideración en el rol responsable de los medios de comunicación en Internet, de tal forma que el ejercicio de la libertad de expresión se realice con observancia de la existencia del derecho al olvido cuya razón es salvaguardar el derecho al libre desarrollo de la 
personalidad, ya que todo ser humano tiene derecho a vivir en paz social y en bienestar.

-Derecho al olvido de acuerdo con el fallo judicial del TJUE, se encuentra referido a que toda persona como titular de sus datos personales tiene el derecho a que se elimine, borre, suprima de Internet cualquier información personal antigua que resulte perjudicial al individuo.

-La colisión entre Derecho al Olvido y la Libertad de expresión representa un naciente conflicto producto del Internet y la nueva tecnología relacionado con la información que circula y que se indexa a través de los motores de búsqueda, la cual carece en muchos casos de un estándar de validez y de información de calidad, perjudicando el libre desarrollo de la personalidad de las personas.

\section{Referencia}

Atienza M. (1997) Tras la Justicia: Una introducción al Derecho y al razonamiento jurídico. Barcelona, España: Editorial Ariel S.A

Álvarez, M. (2015) Derecho al Olvido en Internet: El Nuevo Paradigma de la privacidad en la era digital. Madrid, España: Editorial Reus

Di Pizzo, A (2018) La expansión del derecho al olvido digital. Efectos de <Google Spain $>$ y el Big data e implicaciones del nuevo Reglamento Europeo de Protección de Datos. Barcelona, España: Atelier Libros Jurídicos.

Pérez, L (1993) Derechos Humanos, Estado de Derecho y Constitución, Madrid: Editorial Tecnos.

Rallo, A (2014) El derecho al olvido en Internet. Google versus España. Centro de Estudios Políticos y Constitucionales, Madrid: Boe

Sartori, G (2018) Homo Videns. México: Penguin Random House Grupo Editorial
Simón, P (2012). El régimen constitucional del derecho al olvido digital. Valencia, España: Tirant lo blanch.

\section{Referencias Hemerográficas}

Ahumada Mauricio, R (2017) "Derecho al Olvido y Libertad de Expresión: Análisis prospectivo de una colisión jurídico comunicacional", Universidad Pontificia Universidad Católica de Valparaíso, Chile, 2017.Recuperado de: http:// opac.pucv.cl/pucv_txt/txt-5000/UCC5077_01. pdf

Domínguez, I. (2016). "Hacia la memoria selectiva en Internet: Honor, intimidad y propia imagen en la era digital a partir de la jurisprudencia española." Revista iberoamericana de ciencia tecnología y sociedad, 11(32) Recuperado: http://www.scielo.org.ar/scielo.php?script=sci S185000132016000200004\&lng=es\&tlng=es.

García, T (2016) "El Estado y Liberta de Conciencia" Revista FORSETI No1, Recuperado:https:// revistas.up.edu.pe/index.php/forseti/article/ view/1117/1298

Lévano, V (2020) El Reconocimiento Constitucional del Derecho al Olvido. Tesis para optar el grado académico de Maestro en Derecho Constitucional. Universidad de San Martín de Porres. Lima Perú, Recuperado: https://repositorio.usmp.edu. pe/bitstream/handle/20.500.12727/7365/levano_ vpe.pdf? sequence $=1 \&$ isAllowed $=\mathrm{y}$

López, B (2015) La configuración jurídica del derecho al olvido en el Derecho Español a tenor de la doctrina del TJUE. Recuperado de http:// revistas.uned.es/index.php/derechopolitico/ article/view/15140/13298

Leturia, I (2016) Fundamentos jurídicos del Derecho al Olvido. ¿Un Nuevo derecho de origen europeo o una respuesta típica ante colisiones entre ciertos derechos fundamentales? Revista 
Chilena de Derecho, vol. $43 \mathrm{~N}^{\circ} 1$, Recuperado de: https://scielo.conicyt.cl/scielo.php?script=sci_ abstract\&pid=S0718-34372016000100005\&lng $=$ es\&nrm $=$ iso

Mieres,L(2014)Elderechoalolvidodigital.Fundación Alternativas: Madrid, Recuperado:https:// www.fundacionalternativas.org/public/ storage/laboratorio_documentos_archivos/ e0d97e985163d78a27d6d7c23366767a.pdf

Platero, A (2016) El derecho al olvido en internet. El fenómeno de los motores de búsqueda. Recuperado: https://revistas.udem.edu.co/index. php/opinion/article/view/1726/1670 